\title{
DESEMPENHO DE BEZERRAS DAS RAÇAS PANTANEIRA E GIROLANDO, EM PASTAGENS DE Urochloa decumbens NA ÉPOCA SECA, NO ECÓTONO CERRADO-PANTANAL
}

HEIFERS PERFORMANCE OF THE PANTANEIRAAND GIROLANDO BREED IN PASTURES OF Urochloa decumbens IN DRY PERIOD, IN THE CERRADOPANTANAL ECOTONE

\section{PEDRO GUSTAVO LOESIA LIMA ${ }^{1 *}$, KHEYCIANE VIANA DA SILVA ${ }^{2}$, NÍKOLAS CÁCERES DE OLIVEIRA-BROCHADO ${ }^{3}$, MARCUS VINICIUS MORAIS DE OLIVEIRA ${ }^{4}$}

${ }^{1}$ Programa de pós-graduação em Zootecnia - Universidade Estadual de Maringá Maringá-PR.

2 Programa de pós-graduação em Zootecnia - Universidade Federal do Paraná Curitiba-PR.

${ }^{3}$ Programa de pós-graduação em Zootecnia - Universidade Estadual de Mato Grosso Sul - Aquidauana-MS.

${ }^{4}$ Docente do curso de Zootecnia na Universidade Estadual de Mato Grosso Sul Aquidauana-MS.

* Avenida Colombo, 5790 - Zona 7, Maringá/PR, CEP: 87020-900. E-mail: pedroloesia@gmail.com.

\section{RESUMO}

Objetivou-se com este trabalho verificar o desempenho de animais com diferentes exigências nutricionais, durante o período de estiagem. O período de avaliação foi de 126 dias (14 dias de adaptação e três sub-períodos de 28 dias) em pastagem de capim-braquiária (Urochloa decumbens), com bezerras desmamadas, com idade de 6 a 7 meses, das raças Pantaneira e Girolando (3/4 Holandês $\times 1 / 4 \mathrm{Gir}$ ). As bezerras foram divididas em dois grupos, as que recebiam ração concentrada ao nível de $1 \%$ do peso corpóreo e as que só ficavam na pastagem sem suplementação com concentrado. Em cada período de 28 dias foram coletadas as medidas corporais, o peso dos animais e as respectivas avaliações na pastagem. $O$ consumo de pasto pelos animais foi influenciado pelas dietas, onde os animais que receberam ração consumiram menos capim. A suplementação concentrada proporcionou tanto na raça Pantaneira como na Girolando um aumento do consumo de matéria seca da dieta total. O ganho de peso diário e o ganho de perímetro torácico para as bezerras que receberam ração concentrada foi semelhante para ambas as raças. As bezerras Pantaneiras apresentaram menores dimensões corporais que as Girolando, sendo a menor conversão alimentar observada nos animais Pantaneiros não suplementados.

Palavras-chave: Bovino Pantaneiro. Braquiária. Raças Locais. Recurso Genético Animal.

\section{ABSTRACT}

The objective of this study was to verify the performance of animals with different nutritional requirements during the drought period. The evaluation period was 126 
days (14 days of adaptation and three 28-day sub-periods) in brachiaria grass pasture (Urochloa decumbens), with weaned heifers, aged from 6 to 7 months, from Pantaneira and Girolando breeds. ( $3 / 4$ Dutch x $1 / 4$ Gir). The heifers were divided into two groups, those receiving concentrated feed at $1 \%$ of body weight and those that were only in the pasture without supplementation with concentrate. In each 28-day period, body measurements, animal weight and respective evaluations on pasture were collected. The pasture consumption by the animals was influenced by the diets, whereupon the animals that received feed, consumed less grass. Concentrated supplementation provided both, Pantaneira and Girolando breed, a dry matter intake increases of the total diet. The daily weight gain and thoracic perimeter gain for heifers that were fed with concentrate feed, were similar for both breeds. Pantaneira heifers presented smaller body dimensions than Girolando, being the lowest feed conversion observed in nonsupplemented Pantaneiro animals.

Keywords: Pantaneiro Cattle. Brachiaria. Local Breeds. Animal Genetic Resource.

\section{INTRODUÇÃO}

A criação de bezerras leiteiras exige muita atenção e cuidados especiais, pois a maior porcentagem de mortes é verificada no primeiro ano de vida, estando esses óbitos quase sempre associados a problemas sanitários e nutricionais (DUEÑAS et al., 2017). Nesse aspecto a suplementação de bezerras, especialmente durante o período de seca, torna-se ainda mais relevante, tendo em vista a redução significativa da disponibilidade de biomassa forrageira e da qualidade nutricional do capim, com o aumento de tecidos estruturais da planta e diminuição da fração proteica (NRC, 2001; HILLS et al., 2015).

Os bovinos da raça Pantaneira são um recurso genético naturalizado do Pantanal brasileiro, possuindo características ímpares, tendo em vista que sua base genética é composta essencialmente por animais Bos taurus taurus (BARBOSA et al., 2014). Apesar de no passado predominarem na planície pantaneira, com dezenas de milhares de cabeças, atualmente este grupamento genético se restringe a menos de 500 indivíduos, o que coloca esta espécie em risco de extinção. Diante dessas premissas a raça Pantaneira caracteriza-se como uma opção interessante para a criação pecuária de maneira sustentável, pois são animais de alta rusticidade e com menor exigência nutricional, tendo em vista o seu menor tamanho corporal (DANI; OLIVEIRA, 2013; REZENDE et al., 2014).

Já o Girolando é uma raça sintética, genuinamente brasileira, resultante do cruzamento em proporções variadas entre bovinos das raças Holandesa e Gir. As fêmeas Girolando possuem características fisiológicas e morfológicas perfeitas para a produção de leite nos trópicos, com excelente conformação corporal, adequada pigmentação da pele, elevada capacidade de autorregulação do calor corporal e alta eficiência de pastoreio; o que the confere uma grande resistência, adequada capacidade de adaptação ao meio ambiente e um alto desempenho (BARNABE et al., 2015; ALMEIDA et al., 2016).

Assim, a geração de informações dos índices zootécnicos dos bovinos da raça Pantaneira é vital para a manutenção da espécie, bem como a comparação 
com uma raça já consagrada como a Girolando, em sistemas de criação a pasto. Nesse sentido, esta pesquisa buscou apontar o melhor sistema de criação de bezerras em regime de pastoreio por meio do uso ou não da suplementação concentrada durante o período de estiagem na região de ecótono CerradoPantanal. Bem como comparar as duas raças buscando evidenciar a real capacidade da raça Pantaneira em aproveitar forrageiras de menor qualidade nutricional durante o período de seca.

\section{MATERIAL E MÉTODOS}

O experimento foi conduzido na Universidade Estadual de Mato Grosso do Sul (UEMS), na região do Alto Pantanal Sul-Mato-Grossense, em Aquidauana, MS. As avaliações a campo ocorreram entre os meses de abril a junho. Foram utilizadas 24 bezerras desmamadas de 6 à 7 meses de idade, das raças Pantaneira e Girolando ( $3 / 4$ Holandês x $1 / 4 \mathrm{Gir}$ ), pesando em média 103,90 $\pm 27,90 \mathrm{Kg}$ e $176,85 \pm 32,00 \mathrm{Kg}$, respectivamente. Os animais foram distribuídos em dois grupos (suplementados ou não) com seis animais, sendo doze de cada raça. Cada grupo foi mantido em áreas de pastagem separadas, porém contíguas, sendo a pastagem subdividida em piquetes e ambos os grupos manejados em sistema rotacionado. Segundo o comitê de ética do uso de animais em experimentação/UEMS os mesmos foram certificados conforme o protocolo de número 009 /2014.

O número reduzido de animais utilizado no experimento é justificado pela escassez de indivíduos da raça Pantaneira, isto impediu a inclusão de outros níveis de suplementação. Atualmente, existem cerca de 500 indivíduos puros desta raça mantidos em núcleos de conservação governamentais e de algumas propriedades privadas (DANI; OLIVEIRA, 2013; OLIVEIRA et al., 2015). Assim, para atender os pressupostos de número de repetições para análise estatística frequentista, considerando o número mínimo necessário com um nível de significância de $95 \%$, foram adotados dois níveis de suplementação, conforme Barbosa et al. (2014).

Os animais inicialmente foram identificados com brincos, tratados profilaticamente contra endo/ectoparasitas, e pesados após um jejum alimentar e hídrico prévio de 12 horas, sendo em seguida distribuídos em função da raça e peso corpóreo, obtendo-se homogeneidade dentro de cada tratamento e uma taxa de lotação semelhante nos piquetes. O período pré-experimental foi de 14 dias, tempo necessário para os animais se adaptarem à pastagem e ao suplemento concentrado, e em seguida ocorreu três sub-períodos de 28 dias, totalizando 98 dias de avaliação.

A ração concentrada foi ofertada na proporção de 1,0\% do peso corpóreo $(10 \mathrm{~g} / \mathrm{kg}$ de peso corpóreo) constituída por grão de milho triturado, farelo de soja e sal mineral. Na tabela 1 pode ser observada a composição química dos ingredientes que compuseram a ração, bem como as porcentagens de cada um.

A disponibilização do concentrado foi efetuada diariamente em cocho individual, às $14 \mathrm{~h} 00$, sendo a quantidade oferecida e a sobra pesada diariamente, e uma amostra armazenada em freezer para determinação dos teores de matéria seca (MS), proteína bruta (PB), fibra em detergente neutro (FDN), fibra em detergente ácido (FDA), extrato etéreo (EE) e matéria mineral (MM). 
Tabela 1 - Ingredientes e teores nutricionais do concentrado fornecido aos animais

\begin{tabular}{lc}
\hline Variáveis & $\%$ na Matéria Seca \\
\hline Ingredientes & \\
Grão de milho triturado & 72,00 \\
Farelo de soja & 26,50 \\
Sal mineral & 1,50 \\
\hline Teores Nutricionais & \\
Proteína Bruta & 18,02 \\
Nutrientes Digestíveis Totais & 81,95 \\
Energia Digestível & 3,61 \\
\hline
\end{tabular}

Fonte: os autores.

A pastagem de 1,6 hectares e os respectivos piquetes de 0,16 hectares encontrava-se em condição adequada para pastoreio dos animais. Assim, cada grupo de animais pastoreou em cinco piquetes, sendo o período de pastejo de sete dias, em seguida o piquete foi vedado por 28 dias. A divisão dos piquetes foi efetuada com cerca convencional, composta por postes de madeira e cinco fios de arame liso. Todos os piquetes tiveram sombra, cochos com sal mineral e água disponibilizada em bebedouro.

Para a determinação das condições climáticas foram coletados dados da estação meteorológica da própria instituição, onde foi observado temperaturas com máxima de $34^{\circ} \mathrm{C}$ e mínima de $13^{\circ} \mathrm{C}$, umidade relativa do ar máxima de 97,5 e mínima de 30 , com uma pluviosidade acumulada durante o período experimental de $158,97 \mathrm{~mm}$.

Gaiolas de exclusão, construídas com barra de ferro e revestidas com tela de alambrado, na largura e altura de 2,5 x 2,0 metros, respectivamente, foram utilizados para se determinar a produção de biomassa inicial, o resíduo após o pastejo e a taxa de crescimento diário da planta. Para isso, duas gaiolas foram alocadas no piquete no momento da entrada dos animais e na metade direita da gaiola o capim foi imediatamente cortado rente ao solo, pesado e efetuada a separação das frações de folha, colmo, sementes e material senescente. No final do sétimo dia, o capim existente na metade esquerda da gaiola e na área adjacente externa $(2,5 \times 1,0$ metros) foram cortados, pesados e efetuados a separação das frações de folha, colmo, sementes e material senescente. As frações morfológicas foram utilizadas para a realização de análises bromatológicas, ou seja, de MS, PB, FDN, FDA, EE e MM, determinando-se assim sua qualidade nutritiva. Os teores de Carboidratos Totais (CT) foram estimados pela equação proposta por (SNIFFEN et al., 1992): CT $=\{100-$ [PB $(\% \mathrm{MS})+\mathrm{EE}(\% \mathrm{MS})+\mathrm{MM}(\% \mathrm{MS})]\}$ e os Carboidratos Não Fibrosos (CNF) calculados de acordo com a equação proposta por (HALL, 2000) onde CNF = $\{100-[[\mathrm{PB}(\% \mathrm{MS})-\% \mathrm{~PB}$ derivada da ureia + \% de ureia] + FDN (\%MS) + EE $(\% \mathrm{MS})+\mathrm{MM}(\% \mathrm{MS})]\}$.

Semanalmente também foram retiradas amostras das forragens por meio da técnica de pastejo simulado, com os animais sem um jejum prévio. A coleta foi realizada, por um período de 40 minutos, com início às $7 \mathrm{~h} 00 \mathrm{e}$, portanto, antes da oferta do concentrado. Os avaliadores acompanharam os animais, numa distância inferior a 2 metros, observando o hábito de pastejo e a preferência dos bezerros 
pelos componentes estruturais das forrageiras. Assim, de maneira simultânea e sincronizada com os bovinos, os avaliadores colheram manualmente quatro amostras (10 minutos/amostra) de forragem semelhantes ao que estava sendo selecionado e consumido pelos animais. Após homogeneização do material, uma amostra de $2 \mathrm{~kg}$ foi armazenada em freezer $\left(-20^{\circ} \mathrm{C}\right)$.

No final de cada período experimental as amostras semanais foram homogeneizadas e uma amostra utilizada para determinação das análises de MS, PB, FDN, FDA, CT, CNF, EE, MM. O restante do material foi utilizado para a efetuação na separação das frações de folha, colmo, sementes e material senescente, os quais foram pesados e determinado o seu teor de matéria seca. $A$ digestibilidade in vitro das amostras da planta inteira, coletadas no pastejo simulado, foi efetuada por meio da técnica proposta por (TILLEY; TERRY, 1963). Assim, a amostra composta do período de 28 dias foi descongelada, seca em estufa de $65^{\circ} \mathrm{C}$ com ar forçado e moída em moinho tipo Willey, com peneira de malha de $1 \mathrm{~mm}$, em seguida foi incubada em tubos de vidro, com saliva artificial (solução tampão) e líquido ruminal, coletado de um animal dotado de uma cânula ruminal permanente. A amostra foi mantida em estufa com temperatura em torno de $39^{\circ} \mathrm{C}$ por 48 horas mais $\mathrm{CO}_{2}$ proporcionando um ambiente adequado para a atividade microbiana. Após este período, o meio foi acidificado, com ácido clorídrico e em seguida foi adicionada uma solução de pepsina, permanecendo nestas condições por mais 48 horas, onde ocorreu a digestão enzimática, o qual simula o que ocorre no abomaso e intestino delgado. A matéria orgânica que desapareceu após os dois estágios foi considerada como tendo sido digerida. Logo a seguir ocorreu a filtração, recuperando-se o material residual, ou seja, a fração que não sofreu a digestão e por diferença de 100 foi calculada a fração digestível.

O consumo de forragem pelos animais foi determinado indiretamente através da Fibra em Detergente Ácida Insolúvel (FDAi) como marcador interno. Para isto, foram incubados os alimentos ingeridos (capim e ração) e as fezes $(0,5 \mathrm{~g}$ de amostra, moída em peneira de $1 \mathrm{~mm}$, armazenadas em saco de Tecido Não Tecido (TNT) tratados com acetona PA devidamente identificados) no rúmen de um bovino fistulado com cânula ruminal por 144 horas, sendo estes sacos posteriormente lavados em água corrente e, em seguida, com solução de detergente ácida, segundo o método descrito por (CRAIG et al., 1984).

A produção fecal foi estimada utilizando-se o marcador externo dióxido de titânio $\left(\mathrm{TiO}_{2}\right)$. Assim, do 14 ao $21^{\circ}$ dia de cada período experimental, $10 \mathrm{~g}$ de dióxido de titânio foi incluído na dieta de cada animal. Posteriormente, 50 gramas de amostras de fezes foram coletadas diretamente na ampola retal, sendo estas efetuadas de maneira alternada, as $06 \mathrm{~h} 00$ e $18 \mathrm{~h} 00$ nos dias $19,20,21^{\circ}$ de cada período experimental. Imediatamente após a coleta, as amostras de fezes foram acondicionadas em sacos plásticos, identificadas e congeladas.

O desempenho dos animais foi determinado pelo ganho de peso médio diário, por medições do crescimento corpóreo (alturas de cernelha e garupa, e perímetro torácico), pelo consumo de matéria seca e pela conversão alimentar. A pesagem dos animais foi efetuada em balança mecânica, no início do ensaio e, posteriormente, em intervalos de 28 dias; no período da manhã e após um jejum de sólidos e líquidos de 12 horas, sendo os animais mantidos em baias individuais sem água e alimento. Logo após a pesagem, também se realizou as medições de altura de cernelha, altura de garupa e perímetro torácico. $O$ consumo de matéria seca da ração concentrada foi determinado em função do 
alimento oferecido menos as sobras, sendo determinado em quilos de matéria seca por dia, em percentagem do peso corporal e em função do peso metabólico. Também foi estimado a conversão alimentar, ou seja, a transformação do alimento ingerido em tecido corpóreo.

A digestibilidade aparente dos nutrientes dietéticos (capim e ração) foi efetuada através das amostras de fezes coletadas, de aproximadamente $50 \mathrm{~g}$, diretamente na ampola retal do animal, nos horários de 06h00 e 18h00 intercalados nos dias $19,20,21^{\circ}$, de cada período experimental, respectivamente. Imediatamente após a coleta, as fezes foram acondicionadas em sacos plásticos, identificadas e congeladas. Após o descongelamento, as amostras de cada animal, foram unidas em porções equitativas e homogeneizadas, sendo em seguida determinado os teores de MS, PB, FDN, FDN, CT, CNF, EE e MM. Os teores de Nutrientes Digestíveis Totais foram calculados a partir da equação: NDT ( $\mathrm{g} / \mathrm{dia})=\{(\mathrm{PB}$ ingerida $-\mathrm{PB}$ fezes $)+(\mathrm{CT}$ ingerido $-C T$ fezes $)+[2,25 \times$ (EE ingerido $-E E$ fezes) $]\}$, propostas por (SNIFFEN et al., 1992).

O consumo de matéria seca total (CMST), de capim braquiária mais ração, foi estimado pela equação: CMST $(\mathrm{g} / \mathrm{dia})=$ Produção fecal $(\mathrm{g} / \mathrm{dia}) /(1$ Digestibilidade); sendo os consumos de matéria seca dos nutrientes (CMSNut) estimados através da média ponderal entre a ingestão de forragem e de ração concentrada multiplicada pela percentagem do nutriente, nas respectivas amostras de forragem coletadas no pastejo simulado e da ração concentrada ofertada no cocho. Já os coeficientes de digestibilidade aparente dos nutrientes (DAN) foram estimados pela equação: DAN $(\%)=[((\mathrm{MS}$ ingerida $\times \%$ Nutriente $)-$ (MS excretada $\times \%$ Nutriente) / (MS ingerida $\times \%$ Nutriente)) $\times 100]$.

$O$ delineamento experimental para avaliar a pastagem foi o inteiramente casualizado, sendo o tratamento um: Área que comportou os animais que não receberam suplementação concentrada (AAN) e tratamento dois: Área que comportou os animais suplementados (AAS), com três repetições (sub-períodos de 28 dias). Para consumo, digestibilidade e desempenho dos animais foi utilizado um delineamento inteiramente casualizado, em arranjo fatorial $2 \times 2$ sendo dois níveis de suplementação $(0,0 \%$ e $1,0 \%)$ e duas raças (Pantaneira e Girolando) com seis repetições, sendo as bezerras as unidades experimentais. Os dados foram submetidos à análise de variância e as médias comparadas pelo Teste de Tukey, ao nível de $5 \%$ de probabilidade. A análise estatística foi efetuada por meio do programa estatístico $R$ ( $R$ versão 3.3.0).

\section{RESULTADOS E DISCUSSÃO}

A pastagem que comportou os animais suplementados (AAS) com concentrado ( $1 \%$ do peso corpóreo) apresentou uma maior produção de matéria seca e uma menor porcentagem de folhas $(p<0,05)$, quando comparada à pastagem que manteve os animais não suplementados (AAN) (Tabela 2). Isto se deve ao fato de os bezerros terem obtido energia extra, proveniente do concentrado, assim consumiram menos capim, num clássico efeito substitutivo, proporcionando uma maior taxa de crescimento da planta. Em AAN houve maior pressão de pastejo estimulando o perfilhamento e surgimentos de novas folhas, melhorando a relação folha:colmo.

Uma maior quantidade de material senescente também foi observada $(p<0,05)$ na pastagem que manteve os animais suplementados. Este 
comportamento está ligado à maior área de sombra provocada pelo crescimento das partes da planta, por meio do baixo consumo pelos animais e o alongamento do colmo para expor as folhas em um plano mais alto em busca de luminosidade (CARNEVALLI et al., 2006). Santos et al. (2010) também observaram uma maior proporção de material morto e uma maior massa de colmo verde, durante o deferimento de pastagem de Urochloa decumbens.

Assim, suplementar as bezerras em época seca diminui a pressão de pastejo e melhora a produção de matéria seca do capim, embora haja a diminuição das porcentagens de folha. Em condições de baixa pluviosidade e altas temperaturas, como no caso do Pantanal, esse comportamento é vantajoso, pois abrem permite uma maior taxa de lotação e consequentemente um melhor desempenho das bezerras.

Tabela 2 - Produção do capim Urochloa decumbens, com suas respectivas frações de folha, colmo e material senescente média do período (1 a 84 dias) em função com os níveis de suplementação dos animais

\begin{tabular}{lccccc}
\hline \multirow{2}{*}{ Variável } & \multicolumn{2}{c}{ Tratamentos } & \multirow{2}{*}{ CV $^{4}$} & \multirow{2}{*}{ EP $^{5}$} \\
\cline { 2 - 4 } & AAN $^{2}$ & AAS $^{3}$ & & \\
\hline Produção Matéria Seca $-\mathrm{kg} /$ hectare & $1.382,60 \mathrm{~b}$ & $1.646,08 \mathrm{a}$ & 7,1 & 56,57 \\
Produção matéria seca verde ${ }^{1}-\mathrm{kg} /$ hectare & $1.199,53 \mathrm{a}$ & $1.274,19 \mathrm{a}$ & 4,5 & 31,41 \\
Taxa Crescimento $-\mathrm{kg} / \mathrm{MS} / \mathrm{dia}$ & $120,22 \mathrm{a}$ & $180,92 \mathrm{a}$ & 42,1 & 29,21 \\
\% Folha & $74,07 \mathrm{a}$ & $62,18 \mathrm{~b}$ & 3,7 & 1,32 \\
\% Colmo & $12,79 \mathrm{a}$ & $15,16 \mathrm{a}$ & 12,5 & 0,92 \\
\% Material Senescente & $13,14 \mathrm{~b}$ & $22,66 \mathrm{a}$ & 16,5 & 1,25
\end{tabular}

Notas: *Letras diferentes na linha, indicam diferenças significativas ao nível de $5 \%$ de probabilidade de acordo com o teste de Tukey. ${ }^{1}$ Produção de matéria seca total menos o material senescente; 'Área de permanência do grupo de animais não suplementados; ${ }^{3}$ Área de permanência do grupo de animais suplementados; ${ }^{4}$ Coeficiente de variação; ${ }^{5}$ Erro padrão.

Fonte: os autores.

Quanto à qualidade nutritiva do capim, a mesma não foi influenciada $(p>0,05)$ pela suplementação dos animais (Tabela 3 ). Os elevados teores de MS, FDN, FDA e CT e o reduzido teor de PB refletem a baixa qualidade da forrageira tropical em função da estação do ano (outono-inverno), com consequente efeito negativo sobre a taxa de crescimento e acúmulo de forragem e aumento do teor de fibra e lignificação planta (SIMÕES et al., 2009).

De acordo com Van Soest (1993) os fatores mais limitantes do consumo de volumosos em ruminantes é o teor de FDN, onde valores de constituintes da parede celular devem estar em torno de $55-60 \%$ na matéria seca e no mínimo $7 \%$ de proteína bruta, para haver um bom funcionamento da microbiota ruminal. Santos et al. (2008) ao estudar a composição química da Urochloa decumbens em diferentes níveis de adubação, observaram na época de estiagem valores maiores que $60 \%$ de FDN. Um fator decisivo a ser considerado para a diminuição de FDN, e assim melhorar o consumo pelos animais, refere-se ao período das águas e ao intervalo de corte da forrageira, que, neste estudo, foi numa época de baixa pluviosidade com um diferimento de 28 dias, período esse de restabelecimento fisiológico da planta.

A digestibilidade in vitro da MS do capim braquiária também não foi influenciada significativamente $(p>0,05)$ pela suplementação dos animais 
(Tabela 3), com média para a planta inteira de $51,54 \%$ e $44,78 \%$ para AAS e AAN, respectivamente.

Tabela 3 - Composição química e digestibilidade in vitro do capim Urochloa decumbens em função com os níveis de suplementação dos animais.

\begin{tabular}{|c|c|c|c|c|c|c|}
\hline \multirow{2}{*}{ Variável } & & \multicolumn{2}{|c|}{ Tratamentos } & \multirow{2}{*}{$\mathbf{P}^{4}$} & \multirow{2}{*}{$\mathrm{CV}^{5}$} & \multirow{2}{*}{ EP' } \\
\hline & & AAS $^{2}$ & $\mathrm{AAP}^{3}$ & & & \\
\hline \multirow{4}{*}{$\%$ Matéria Seca } & Planta Inteira & $24,00 a$ & $29,99 a$ & 0,073 & 5,2 & 0,72 \\
\hline & Folha & $19,93 a$ & $23,95 a$ & 0,372 & 16,4 & 1,88 \\
\hline & Colmo & $27,10 \mathrm{a}$ & $28,84 \mathrm{a}$ & 0,627 & 4,2 & 0,69 \\
\hline & Mat. Senesc. ${ }^{1}$ & $45,85 a$ & $46,49 a$ & 0,951 & 30,5 & 8,07 \\
\hline \multirow{4}{*}{ \% Proteína Bruta } & Planta Inteira & $6,82 a$ & $5,66 a$ & 0,662 & 45,6 & 1,79 \\
\hline & Folha & $8,35 \mathrm{a}$ & $7,94 \mathrm{a}$ & 0,911 & 44,4 & 2,14 \\
\hline & Colmo & $2,92 \mathrm{a}$ & $3,11 \mathrm{a}$ & 0,805 & 30,7 & 0,51 \\
\hline & Mat. Senesc. ${ }^{1}$ & $1,50 \mathrm{a}$ & $1,29 a$ & 0,453 & 18,7 & 0,13 \\
\hline \multirow{4}{*}{ \% Fibra Detergente Neutro } & Planta Inteira & $64,12 \mathrm{a}$ & $65,81 \mathrm{a}$ & 0,682 & 4,9 & 3,33 \\
\hline & Folha & $66,11 \mathrm{a}$ & 68,93 a & 0,609 & 6,9 & 2,76 \\
\hline & Colmo & $81,73 a$ & $82,52 \mathrm{a}$ & 0,746 & 3,3 & 1,57 \\
\hline & Mat. Senesc. ${ }^{1}$ & $41,92 \mathrm{a}$ & $40,16 \mathrm{a}$ & 0,242 & 2,6 & 0,62 \\
\hline \multirow{4}{*}{ \% Fibra Detergente Ácido } & Planta Inteira & $25,51 \mathrm{a}$ & $27,36 a$ & 0,350 & 1,6 & 0,26 \\
\hline & Folha & $23,42 a$ & $24,60 \mathrm{a}$ & 0,134 & 1,4 & 0,19 \\
\hline & Colmo & $31,61 \mathrm{a}$ & $32,58 \mathrm{a}$ & 0,239 & 2,7 & 0,49 \\
\hline & Mat. Senesc. ${ }^{1}$ & $30,46 \mathrm{a}$ & $31,81 \mathrm{a}$ & 0,226 & 1,6 & 0,29 \\
\hline \multirow{4}{*}{ \% Carboidratos Totais } & Planta Inteira & $75,89 a$ & $77,71 \mathrm{a}$ & 0,451 & 3,5 & 1,55 \\
\hline & Folha & $73,78 a$ & 75,04 a & 0,708 & 4,4 & 1,90 \\
\hline & Colmo & $82,44 a$ & $82,53 a$ & 0,875 & 0,3 & 0,13 \\
\hline & Mat. Senesc. ${ }^{1}$ & $81,77 \mathrm{a}$ & $81,57 \mathrm{a}$ & 0,626 & 0,4 & 0,19 \\
\hline \multirow{4}{*}{ \% Carboidratos Não Fibrosos } & Planta Inteira & $10,88 a$ & $8,76 a$ & 0,090 & 1,3 & 0,19 \\
\hline & Folha & $8,84 a$ & $8,05 \mathrm{a}$ & 0,575 & 5,0 & 0,23 \\
\hline & Colmo & $5,36 a$ & $5,01 \mathrm{a}$ & 0,747 & 22,7 & 0,65 \\
\hline & Mat. Senesc. ${ }^{1}$ & $24,92 \mathrm{a}$ & $25,70 \mathrm{a}$ & 0,285 & 1,3 & 0,19 \\
\hline \multirow{4}{*}{ \% Extrato Etéreo } & Planta Inteira & $1,36 a$ & $1,38 a$ & 0,761 & 6,7 & 0,05 \\
\hline & Folha & $1,38 \mathrm{a}$ & $1,42 a$ & 0,657 & 5,9 & 0,04 \\
\hline & Colmo & $0,59 a$ & $0,36 a$ & 0,451 & 51,4 & 0,10 \\
\hline & Mat. Senesc. ${ }^{1}$ & $1,96 \mathrm{a}$ & $2,06 \mathrm{a}$ & 0,460 & 3,5 & 0,04 \\
\hline \multirow{4}{*}{ \% Matéria Mineral } & Planta Inteira & $5,94 \mathrm{a}$ & $5,24 a$ & 0,091 & 6,8 & 0,20 \\
\hline & Folha & $6,49 a$ & $5,60 \mathrm{a}$ & 0,057 & 5,8 & 0,18 \\
\hline & Colmo & $4,05 a$ & $4,00 \mathrm{a}$ & 0,903 & 9,6 & 0,22 \\
\hline & Mat. Senesc. ${ }^{1}$ & $4,78 \mathrm{a}$ & $5,08 \mathrm{a}$ & 0,582 & 10,7 & 0,31 \\
\hline \multirow{4}{*}{$\begin{array}{l}\text { Digestibilidade } \\
\text { In Vitro - \% }\end{array}$} & Planta Inteira & $51,54 \mathrm{a}$ & $44,78 \mathrm{a}$ & 0,226 & 10,9 & 3,2 \\
\hline & Folha & $61,51 \mathrm{a}$ & $59,61 \mathrm{a}$ & 0,784 & 12,3 & 4,37 \\
\hline & Colmo & $39,93 a$ & $42,99 a$ & 0,144 & 3,1 & 0,70 \\
\hline & Mat. Senesc. ${ }^{1}$ & $5,28 a$ & $5,67 a$ & 0,966 & 7,9 & 0,26 \\
\hline
\end{tabular}

Notas: *Letras diferentes na linha, indicam diferenças significativas ao nível de $5 \%$ de probabilidade de acordo com o teste de Tukey. 'Material senescente; ${ }^{2}$ Área de permanência do grupo de animais não suplementados; ${ }^{3}$ Área de permanência do grupo de animais suplementados; ${ }^{4}$ Probabilidade; ${ }^{5}$ Coeficiente de variação; ${ }^{6}$ Erro padrão.

Fonte: os autores.

A baixa digestibilidade do capim está relacionada ao amadurecimento da planta, onde mais alta será a lignificação de suas partes e pior será a digestibilidade, porém a diferença encontrada no acumulo de forragem entres os tratamentos não influenciaram a digestibilidade in vitro da mesma. Resultados semelhantes foram encontrados por Paciullo et al. (2009) quando avaliavam as 
características de pastagens de Urochloa decumbens, os quais observaram DIV de 47,8\% em época de seca. Krutzmann et al. (2014) ao avaliarem forrageiras consorciadas, relataram que há um decréscimo da DIV quando manejadas próximas a época de seca.

A suplementação concentrada proporcionou $(p<0,05)$ tanto na raça Pantaneira como na Girolando um aumento do consumo de MS da dieta total, com elevação média de 47,8 e $142,4 \%$ no consumo de MS expresso em percentagem do peso corpóreo, respectivamente (Tabela 4). Evidenciando assim, a maior capacidade da raça Girolando em aproveitar alimentos não fibrosos, consequência do seu maior volume abdominal, que comporta uma maior quantidade de alimentos e favorece o desenvolvimento microbiano ruminal.

Tabela 4 - Consumos expressos na matéria seca, em bezerras das raças Pantaneira e Girolando mantidos em pastagem de capim Urochloa decumbens de acordo com os níveis de suplementação.

\begin{tabular}{|c|c|c|c|c|c|}
\hline \multirow{2}{*}{ Variáveis } & \multirow{2}{*}{ Alimento } & \multicolumn{2}{|c|}{ Pantaneira } & \multicolumn{2}{|c|}{ Girolando } \\
\hline & & 0,0 & $1,0 \% \mathrm{PC}^{10}$ & 0,0 & $1,0 \% \mathrm{PC}^{10}$ \\
\hline \multirow{3}{*}{$\mathrm{MS}^{1}$ (kg/dia) } & Concentrado & $0,0 \mathrm{c}$ & $1,16 \mathrm{~b}$ & $0,0 \mathrm{c}$ & $1,96 \mathrm{a}$ \\
\hline & Pasto & $1,41 \mathrm{~b}$ & $1,13 b$ & $1,69 b$ & $2,71 \mathrm{a}$ \\
\hline & Total & $1,41 \mathrm{~b}$ & $2,29 \mathrm{~b}$ & $1,69 b$ & $4,67 \mathrm{a}$ \\
\hline \multirow{3}{*}{$\begin{array}{c}\text { MS }^{1} \\
\text { \%Peso Corporeo }\end{array}$} & Concentrado & $0,0 \mathrm{~b}$ & $1,0 \mathrm{a}$ & $0,0 \mathrm{~b}$ & $1,0 \mathrm{a}$ \\
\hline & Pasto & $1,34 \mathrm{a}$ & $0,97 \mathrm{a}$ & $0,99 a$ & $1,40 \mathrm{a}$ \\
\hline & Total & $1,34 \mathrm{~b}$ & $1.97 \mathrm{a}$ & $0,99 \mathrm{~b}$ & $2,40 a$ \\
\hline \multirow{3}{*}{$\begin{array}{c}\text { MS }^{1} \\
\text { \%Peso Metabólico }\end{array}$} & Concentrado & $0,0 \mathrm{c}$ & $32,68 \mathrm{~b}$ & $0,0 \mathrm{c}$ & $37,35 a$ \\
\hline & Pasto & $42,8 \mathrm{a}$ & $31,92 a$ & $35,77 a$ & $52,27 a$ \\
\hline & Total & $42,8 \mathrm{c}$ & $64,6 \mathrm{~b}$ & $35,77 \mathrm{c}$ & $89,62 \mathrm{a}$ \\
\hline \multirow{3}{*}{$\mathrm{PB}^{2}$ (g/dia) } & Concentrado & $0,0 \mathrm{c}$ & $198,8 \mathrm{~b}$ & $0,0 \mathrm{c}$ & $336,5 \mathrm{a}$ \\
\hline & Pasto & $154,9 \mathrm{~b}$ & $119,1 \mathrm{~b}$ & $185,9 \mathrm{~b}$ & 284,8 a \\
\hline & Total & $154,9 \mathrm{c}$ & $317,9 \mathrm{~b}$ & $185,9 \mathrm{c}$ & 621,3 a \\
\hline \multirow{3}{*}{$\mathrm{FDN}^{3}$ (g/dia) } & Concentrado & $0,0 \mathrm{c}$ & $97,08 \mathrm{~b}$ & $0,0 \mathrm{c}$ & $164,3 a$ \\
\hline & Pasto & $886,0 \mathrm{~b}$ & $738,5 \mathrm{~b}$ & $1063,0 \mathrm{~b}$ & $1766,0 \mathrm{a}$ \\
\hline & Total & $886,0 \mathrm{~b}$ & $835,6 \mathrm{~b}$ & $1063,0 \mathrm{~b}$ & $1931,0 \mathrm{a}$ \\
\hline \multirow{3}{*}{$\mathrm{FDA}^{4}(\mathrm{~g} / \mathrm{dia})$} & Concentrado & $0,0 \mathrm{c}$ & $45,67 \mathrm{~b}$ & $0,0 \mathrm{c}$ & $77,32 \mathrm{a}$ \\
\hline & Pasto & $331,3 \mathrm{~b}$ & $244,9 \mathrm{~b}$ & $397,6 \mathrm{ab}$ & 585,8 a \\
\hline & Total & $331,3 \mathrm{~b}$ & $290,6 \mathrm{~b}$ & $397,6 \mathrm{~b}$ & $663,2 \mathrm{a}$ \\
\hline \multirow{3}{*}{$\mathrm{CT}^{5}$ (g/dia) } & Concentrado & $0,0 \mathrm{c}$ & $863,6 \mathrm{~b}$ & $0,0 \mathrm{c}$ & $1462,0 \mathrm{a}$ \\
\hline & Pasto & $1095,0 \mathrm{~b}$ & $878,1 \mathrm{~b}$ & $1314,0 \mathrm{~b}$ & $2100,0 \mathrm{a}$ \\
\hline & Total & $1095,0 \mathrm{~b}$ & $1742,0 \mathrm{~b}$ & $1314,0 \mathrm{~b}$ & $3562,0 \mathrm{a}$ \\
\hline \multirow{3}{*}{$\mathrm{CNF}^{6}$ (g/dia) } & Concentrado & $0,0 \mathrm{c}$ & $761,4 \mathrm{~b}$ & $0,0 \mathrm{c}$ & 1289,0 a \\
\hline & Pasto & $162,8 a b$ & $100,7 \mathrm{~b}$ & 195,3 a & $240,9 a$ \\
\hline & Total & $162,8 \mathrm{c}$ & $862,2 \mathrm{~b}$ & $195,3 \mathrm{c}$ & 1530,0 a \\
\hline \multirow{3}{*}{$\mathrm{EE}^{7}$ (g/dia) } & Concentrado & $0,0 \mathrm{c}$ & $36,74 \mathrm{~b}$ & $0,0 \mathrm{c}$ & $62,19 a$ \\
\hline & Pasto & $25,84 \mathrm{~b}$ & $25,84 \mathrm{~b}$ & $31,01 \mathrm{~b}$ & 57,99 a \\
\hline & Total & $25,84 \mathrm{c}$ & $60,98 \mathrm{~b}$ & $31,01 \mathrm{c}$ & $120,2 \mathrm{a}$ \\
\hline \multirow{3}{*}{$\mathrm{MM}^{8}$ (g/dia) } & Concentrado & $0,0 \mathrm{c}$ & $47,22 \mathrm{~b}$ & $0,0 \mathrm{c}$ & $79,93 a$ \\
\hline & Pasto & $124,5 \mathrm{~b}$ & $100,1 \mathrm{~b}$ & $149,4 \mathrm{~b}$ & 239,4 a \\
\hline & Total & $124,5 \mathrm{~b}$ & $147,3 \mathrm{~b}$ & 149,4 b & 319,4 a \\
\hline $\mathrm{NDT}^{9}(\mathrm{~g} / \mathrm{d})$ & Total & $1308,0 \mathrm{c}$ & $1985,0 \mathrm{~b}$ & $1569,0 \mathrm{bc}$ & $3761,0 a$ \\
\hline
\end{tabular}

Notas: "Letras diferentes na linha, indicam diferenças significativas ao nível de $5 \%$ de probabilidade de acordo com o teste de Tukey. 'Matéria seca; ${ }^{2}$ Proteina bruta; ${ }^{3} \mathrm{Fibra}$ em detergente neutro; ${ }^{4}$ Fibra em detergente ácido; ${ }^{5}$ Carboidratos totais; ${ }^{6}$ Carboidratos não fibrosos; ${ }^{7}$ Extrato etéreo; ${ }^{8}$ Matéria mineral; ${ }^{9}$ Nutrientes digestíveis Totais; ${ }^{10}$ Fornecimento de ração concentrada ao nível de $1 \%$ do peso corpóreo (10g/Kg de PC).

Fonte: os autores. 
Em relação ao consumo de pasto ( $\mathrm{Kg}$ de $\mathrm{MS} / \mathrm{dia}$ ), verificou-se uma tendência $(p<0,17)$ de menor ingestão da raça Pantaneira e um efeito significativo $(p<0,05)$ de aumento para a raça Girolando, indicando assim efeitos substitutivos e aditivos, respectivamente. Como consequência dos consumos também foi observada em ambas as raças diferenças estatísticas $(p<0,05)$ nos consumos dos nutrientes PB, FDN, FDA, CT, CNF, EE e MM para concentrado e dieta total ingerida, bem como de NDT (Tabela 4). Quando se submete animais a dietas com alta porcentagem de fibra, apresentando reduzida concentração energética e maior volume físico, o consumo apresenta limitação por enchimento, ou seja, devido à distensão ruminal decorrente da alta ingestão de alimentos fibrosos, há uma diminuição do consumo de MS (BIANCHINI et al., 2007).

Notoriamente a digestibilidade da PB, CT, CNF, FDA e EE foi melhorada significativamente $(p<0,05)$ com a inclusão do concentrado na dieta dos animais para ambas as raças. Já para as demais variáveis de digestibilidade da MS, FDN, MM e EE bem como a ED, verifica-se uma superioridade $(p<0,05)$ da raça Girolando em relação à capacidade de aproveitamento dos nutrientes ingeridos, sendo a melhora da digestibilidade da MS nos animais suplementados com concentrado de 16,1 e $19,5 \%$ para as raças Pantaneira e Girolando, respectivamente (Tabela 5 ).

Tabela 5 - Digestibilidades expressas na matéria seca, em bezerras das raças Pantaneira e Girolando mantidos em pastagem de capim Urochloa decumbens, de acordo com os níveis de suplementação.

\begin{tabular}{|c|c|c|c|c|}
\hline \multirow{2}{*}{ Variáveis } & \multicolumn{2}{|c|}{ Pantaneira } & \multicolumn{2}{|c|}{ Girolando } \\
\hline & 0,0 & $1,0 \% \mathrm{PC}^{11}$ & 0,0 & $1,0 \% \mathrm{PC}^{11}$ \\
\hline $\mathrm{MS}^{1}$ & $52,24 \mathrm{c}$ & $60,67 \mathrm{~b}$ & $56,73 \mathrm{bc}$ & $67,77 \mathrm{a}$ \\
\hline $\mathrm{PB}^{2}$ & $49,14 \mathrm{~b}$ & 66,62 a & $54,19 \mathrm{~b}$ & 72,64 a \\
\hline $\mathrm{FDN}^{3}$ & $44,76 \mathrm{c}$ & $54,86 \mathrm{~b}$ & $46,74 \mathrm{c}$ & 63,56 a \\
\hline $\mathrm{FDA}^{4}$ & $29,98 \mathrm{c}$ & $45,75 a b$ & $37,1 \mathrm{bc}$ & 55,46 a \\
\hline $\mathrm{CT}^{5}$ & $56,7 \mathrm{~b}$ & $62,6 a b$ & 60,97 & 69,99 a \\
\hline $\mathrm{CNF}^{6}$ & $76,65 \mathrm{c}$ & 91,51 a & $82,11 \mathrm{~b}$ & 94,14 a \\
\hline $\mathrm{EE}^{7}$ & $42,68 \mathrm{~b}$ & 63,35 a & $48,06 \mathrm{~b}$ & $69,0 \mathrm{a}$ \\
\hline $\mathrm{MM}^{8}$ & $20,88 \mathrm{c}$ & $24,96 \mathrm{bc}$ & $26,28 \mathrm{~b}$ & $34,15 a$ \\
\hline $\mathrm{NDT}^{9}$ & $47,32 d$ & $60,87 \mathrm{~b}$ & $51,66 \mathrm{c}$ & 63,23 a \\
\hline ED $10(\mathrm{kcallgMS})$ & $2.08 d$ & $2.68 \mathrm{~b}$ & $2.28 \mathrm{c}$ & $2.79 a$ \\
\hline
\end{tabular}

Notas: *Letras diferentes na linha, indicam diferenças significativas ao nível de $5 \%$ de probabilidade de acordo com o teste de Tukey. ${ }^{1}$ Matéria seca; ${ }^{2}$ Proteina bruta; ${ }^{3}$ Fibra em detergente neutro; ${ }^{4}$ Fibra em detergente ácido; ${ }^{5}$ Carboidratos totais; ${ }^{6}$ Carboidratos não fibrosos; ${ }^{7}$ Extrato etéreo; ${ }^{8}$ Matéria mineral; ${ }^{9}$ Nutrientes digestíveis Totais; ${ }^{10}$ Energia digestível; ${ }^{11}$ Fornecimento de ração concentrada ao nível de $1 \%$ do peso corpóreo $(10 \mathrm{~g} / \mathrm{Kg}$ de PC).

Fonte: os autores.

Não houveram diferenças significativas entre as bezerras suplementadas ou não, apenas entre raças. Assim, as bezerras Pantaneiras apresentaram menores dimensões corporais $(p<0.05)$, tanto nas medidas inicias como nas finais. As bezerras Pantaneiras iniciaram com 22; 18 e $19 \mathrm{~cm}$ e terminaram o experimento com 23; 19 e $20 \mathrm{~cm}$ menores que as bezerras Girolando, para as 
variáveis perímetro torácico, altura de cernelha e garupa, respectivamente. As bezerras de ambas as raças possuíram maior altura de garupa do que de cernelha. A diferença entre altura de garupa e cernelha para as medias inicias e finais foram as mesmas para ambas as raças, com medidas de $4 \mathrm{~cm}$ e $5 \mathrm{~cm}$ para as bezerras Pantaneiras e Girolando, respectivamente (Figura 1).

Figura 1 - Dimensões corporais (metros) de bezerras desmamadas das raças Pantaneiras e Girolando

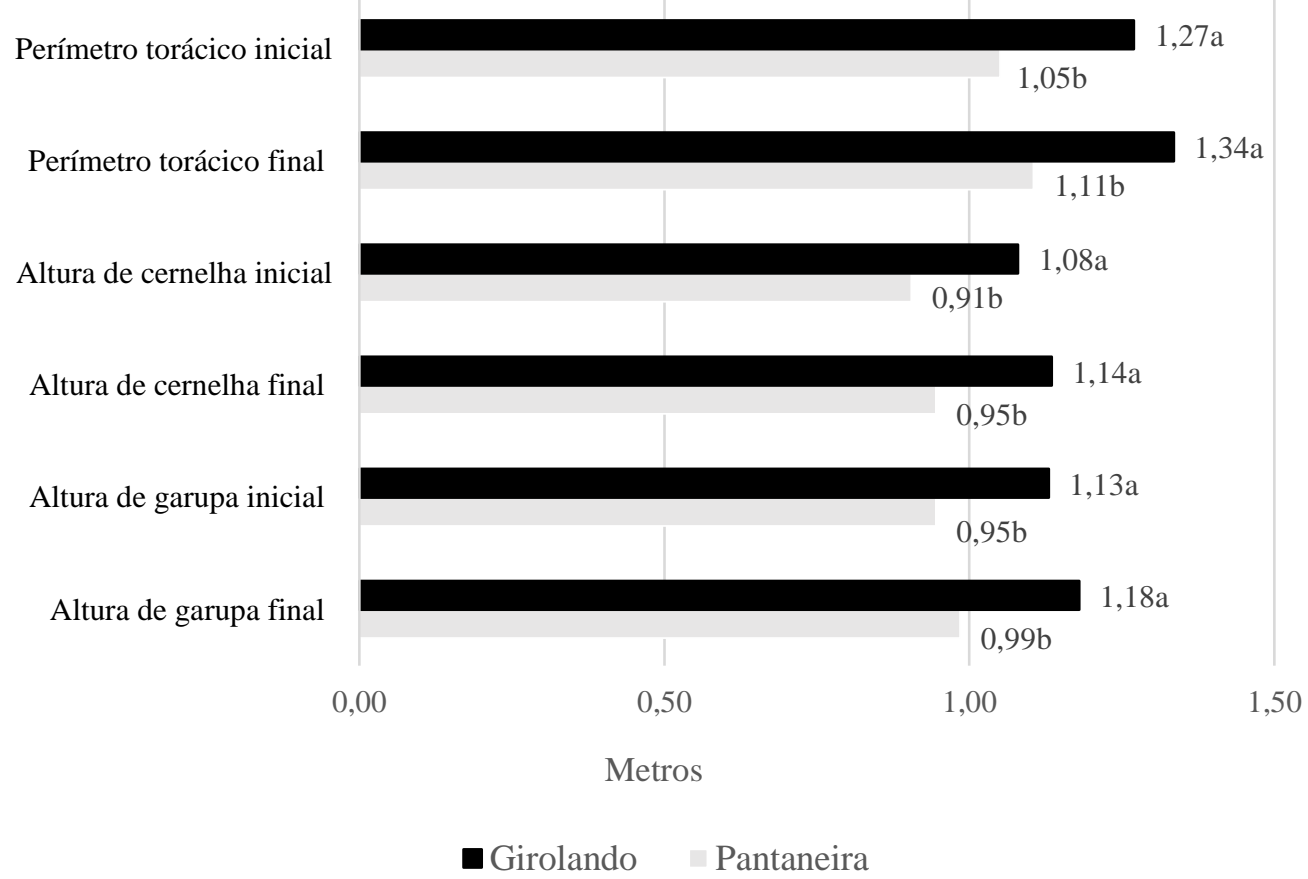

Notas: Letras díspares, indicam diferenças significativas entre raças, ao nível de $5 \%$ de probabilidade de acordo com o teste de Tukey.

Fonte: os autores.

Quanto ao peso corpóreo as bezerras Pantaneiras foram inferiores $(p<0.05)$ às bezerras Girolando (Figura 2). Ao longo do experimento as bezerras Pantaneiras ganharam $19,4 \mathrm{Kg}$ já as Girolando ganharam $25,05 \mathrm{~kg}$, ou seja, $5,65 \mathrm{Kg}$ a mais.

Todavia, não houve diferenças estatísticas entre as raças no ganho de peso diário (GMD) dos animais, com média de 140,0 e 150,0 g/dia; para o grupo não suplementado com concentrado e de 321,0 e 448,0 g/dia para o grupo suplementado, das raças Pantaneira e Girolando, respectivamente. Porém, foi verificado um efeito significativo $(P<0,05)$ da suplementação concentrada em ambas as raças, com incremento no GMD de 128,6 e $200,0 \%$ para as raças Pantaneira e Girolando, respectivamente (Tabela 6).

Signoretti et al. (2013) avaliando novilhas Girolando, com predominância de grau de sangue $3 / 4$ a $7 / 8$ Holandês, idade inicial de 13,6 meses e peso corporal inicial médio de $176,8 \mathrm{~kg}$, observaram um ganho de peso médio de $678 \mathrm{~g} / \mathrm{dia}$ quando manejadas em pastagens de Brachiaria brizantha na época das águas. Já Teodoro et al. (2013) avaliando o desempenho de novilhas Pantaneiras relataram um ganho médio diário de $600 \mathrm{~g} / \mathrm{dia}$. 
Figura 2 - Peso corpóreo inicial e final de bezerras desmamadas das raças Pantaneiras e Girolando.

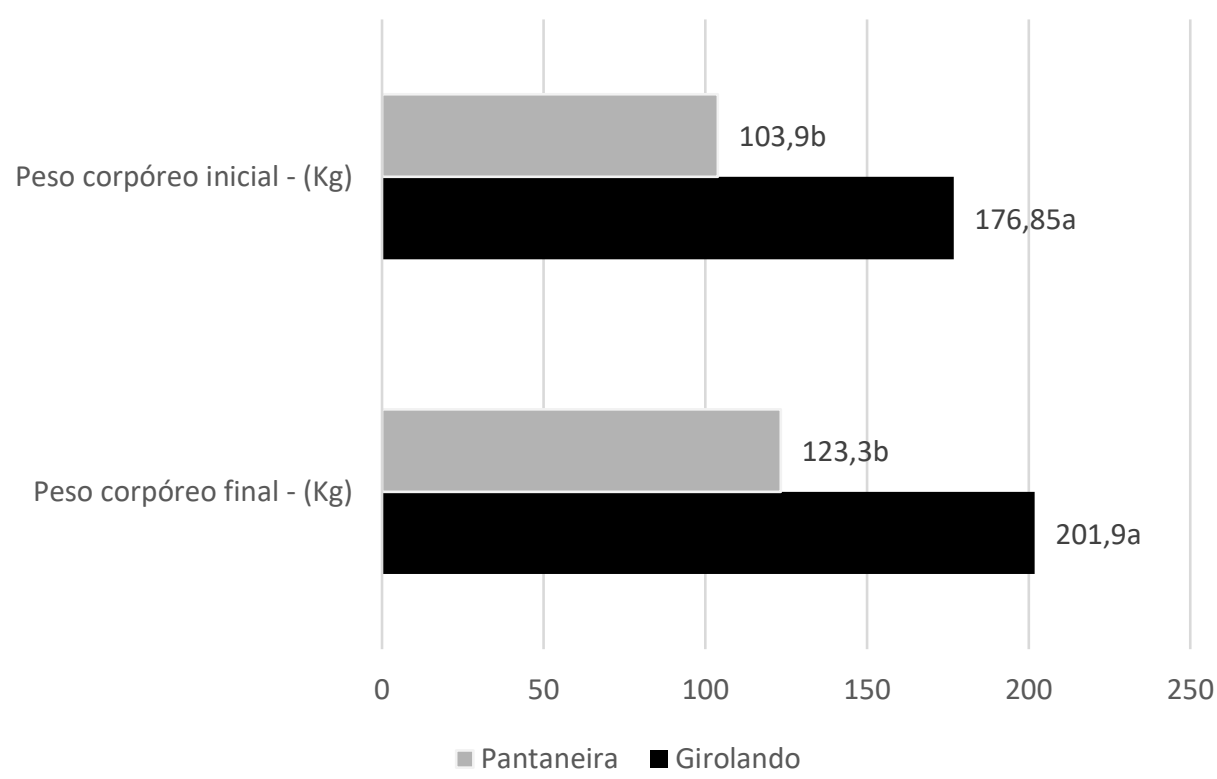

Notas Letras díspares, indicam diferenças significativas entre raças, ao nível de $5 \%$ de probabilidade de acordo com o teste de Tukey.

Fonte: os autores.

Tabela 6 - Ganho de peso médio diário, conversão alimentar, ganho de perímetro torácico e ganho de alturas de cernelha e garupa de bezerras das raças Pantaneira e Girolando mantidos em pastagem de capim Urochloa decumbens, de acordo com os níveis de suplementação.

\begin{tabular}{|c|c|c|c|c|}
\hline \multirow{2}{*}{ Variáveis } & \multicolumn{2}{|c|}{ Raça Pantaneira } & \multicolumn{2}{|c|}{ Raça Girolando } \\
\hline & 0,0 & $1,0 \% \mathrm{PC}^{1}$ & 0,0 & $1,0 \% \mathrm{PC}^{1}$ \\
\hline Ganho médio diário - (g/dia) & $0,140 \mathrm{~b}$ & $0,321 \mathrm{a}$ & $0,149 b$ & 0,448 a \\
\hline Conversão alimentar & $10,07 a b$ & $7,13 \mathrm{c}$ & $11,34 a$ & $10,42 a b$ \\
\hline Ganho perímetro torácico - $(\mathrm{cm})$ & $4,5 \mathrm{~b}$ & $7,58 \mathrm{a}$ & $3,75 b$ & 9,16 a \\
\hline $\begin{array}{l}\text { Ganho altura de cernelha - } \\
\text { (cm) }\end{array}$ & $3,16 \mathrm{~b}$ & $4,75 a b$ & $4,0 \mathrm{~b}$ & $6,25 a$ \\
\hline Ganho altura de garupa - $(\mathrm{cm})$ & $3,5 \mathrm{~b}$ & $4,66 \mathrm{ab}$ & $4,16 a b$ & 6,58 a \\
\hline
\end{tabular}

Notas: *Letras diferentes na linha, indicam diferenças significativas ao nível de $5 \%$ de probabilidade de acordo com o teste de Tukey. ${ }^{1}$ Fornecimento de ração concentrada ao nível de $1 \%$ do peso corpóreo $(10 \mathrm{~g} / \mathrm{Kg}$ de $\mathrm{PC})$.

Fonte: os autores.

Animais submetidos a baixos níveis nutricionais entram na puberdade mais tardiamente; e considerando que bezerras leiteiras necessitam de um ganho de peso médio diário, do nascimento à concepção, próximo a $500 \mathrm{~g} / \mathrm{dia}$, faz-se necessário a suplementação desses animais durante a época da seca, quando manejadas em pastagem de qualidade inferior (CAMPOS; LIZIEIRE, 2005; DAVIS RINCKER et al., 2011).

Uma menor conversão alimentar (CA) foi observada nos animais Pantaneiros suplementados com concentrado, sendo necessária a ingestão de $7 \mathrm{~kg}$ de matéria seca para a produção de $1 \mathrm{~kg}$ de peso corpóreo. Teodoro et al. 
(2013) obtiveram CA de $(10,9)$ ao observarem desempenho de bezerras desmamadas aos 10 meses de idade da raça Pantaneira alimentadas com feno altamente fibroso, valor este superior ao observado neste trabalho, porém compatível com a maior idade dos animais e da fonte volumosa utilizada. Os bovinos Pantaneiros foram submetidos a um processo de seleção natural, resultando em animais aptos a sobreviverem em condições de dietas de baixa qualidade nutricional, onde uma maior eficiência alimentar é fundamental (MAZZA et al., 1992).

Os ganhos de altura de cernelha e garupa foram estatisticamente superiores $(p<0,05)$ nos Girolando suplementados com concentrado. Já o ganho de perímetro torácico, foi semelhante para ambas as raças, com média de 4,5 e $3,75 \mathrm{~cm}$ para os mais não suplementados e de 7,58 e $9,16 \mathrm{~cm}$ para os animais suplementados da raça Pantaneira e Girolando, respectivamente (Tabela 6).

\section{CONCLUSÃO}

Durante o período de outono-inverno, a produção de biomassa da Urochloa decumbens é influenciada positivamente pelo fornecimento de suplementação concentrada aos animais, porém não havendo diferença quanto ao valor nutritivo. Indicando um manejo alternativo, tanto para a pastagem quanto para o desempenho dos animais, que pode ser adotado em condições semelhantes a este experimento.

O fornecimento de ração concentrada proporcionou um melhor desempenho dos animais em ambas as raças, garantindo o desenvolvimento necessário para a vida reprodutiva futura.

As bezerras Pantaneiras possuem menor tamanho corporal do que as Girolando, sendo as Pantaneiras não suplementadas mais eficientes em aproveitar a Urochloa decumbens na época de estiagem, com uma menor conversão alimentar.

Ambas as raças tiveram o mesmo desempenho quanto ao ganho de peso diário e ganho de perímetro torácico quando receberam ração concentrada ao nível de $1 \%$ do peso corpóreo.

\section{AGRADECIMENTOS}

Este trabalho foi financiado pela CAPES, CNPq, FUNDECT, MCT, MEC, Governo Federal, Centro de Pesquisa do Pantanal (CPP) e Rede Pró-CentroOeste.

\section{REFERÊNCIAS}

ALMEIDA, G. L. P. et al. Thermal efficiency of individual shelters for girolando calves in brazilian semi-arid regions. Engenharia Agrícola, v. 36, n. 1, p. 13-23, 2016.

BARBOSA, B. R. P. et al. Tolerância ao calor em bovinos das raças Nelore branco, Nelore vermelho e Pantaneira. Revista Brasileira de Saúde e Produção Animal, v. 15, n. 4, p. 854-865, 2014.

BARNABE, J. M. C. et al. Conforto termico e desempenho de bezerras Girolando 
alojadas em abrigos individuais com diferentes coberturas. Revista Brasileira de Engenharia Agrícola e Ambiental, v. 19, n. 5, p. 481-488, 2015.

BIANCHINI, W. et al. Importância da fibra na nutrição de bovinos. Revista eletrónica de Veterinária, v. 8, n. 2, p. 1-14, 2007.

CAMPOS, O. F.; LIZIEIRE, R. S. Criação de bezerras em rebanhos leiteiros. Juiz de Fora: Embrapa Gado de leite, 2005.

CARNEVALLI, R. A. et al. Herbage production and grazing losses in Panicum maximum cv. Mombaca under four grazing managements. Tropical Grasslands, v. 40, n. 3, p. 165-176, 2006.

CRAIG, W. M. et al. In vitro inoculum enriched with particle associated microorganisms for determining rates of fiber digestion and protein degradation. Journal of Dairy Science, v. 67, n. 12, p. 2902-2909, 1984.

DANI, S. U.; OLIVEIRA, M. V. M. DE. Cattle, cheese and conservation. Nature, v. 502 , n. 7472 , p. $448,2013$.

DAVIS RINCKER, L. E. et al. Effect of intensified feeding of heifer calves on growth, pubertal age, calving age, milk yield, and economics. Journal of Dairy Science, v. 94, n. 7, p. 3554-3567, 2011.

DUEÑAS, F. et al. Short communication: Characterization of Salmonella phages from dairy calves on farms with history of diarrhea. Journal of Dairy Science, v. 100, n. 3, p. 2196-2200, 2017.

HALL, M. B. Neutral detergent-soluble carbohydrates: nutritional relevance and analysis, a laboratory manual. Gainesville: University of Florida, 2000.

HILLS, J. L. et al. Invited review: An evaluation of the likely effects of individualized feeding of concentrate supplements to pasture-based dairy cows. Journal of dairy science, v. 98, n. 3, p. 1363-1401, 2015.

KRUTZMANN, A. et al. Produção Animal , Composição Química E Digestibilidade De Forrageiras Tropicais Em Sistema De Integração LavouraPecuária. BioScience Journal, v. 30, n. 2, p. 491-501, 2014.

MAZZA, M. C. M. et al. Phenotypical characterization of Pantaneiro cattle in Brasil. Archivos de Zootecnia, v. 41, p. 477-484, 1992.

NRC. National Resarch Council - Nutrient requeriments of dairy cattle. 7.rev.ed. ed. Washinton, D.C: [s.n.].

PACIULLO, D. S. C. et al. Características do pasto e desempenho de novilhas em sistema silvipastoril e pastagem de braquiária em monocultivo. Pesquisa Agropecuaria Brasileira, v. 44, n. 11, p. 1528-1535, 2009.

REZENDE, M. P. G. et al. Caracterização zoométrica de novilhas remanescentes 
da raça Pantaneira. Ciência Rural, v. 44, n. 4, p. 706-709, 2014.

SANTOS, L. C. et al. Produção e composição química da Brachiaria brizantha e Brachiaria decumbens submetidas a diferentes adubações. Ciência Animal Brasileira, v. 9, n. 4, p. 856-866, 2008.

SANTOS, M. E. R. et al. Estrutura do capim-braquiária durante o diferimento da pastagem. Acta Scientiarum - Animal Sciences, v. 32, n. 2, p. 139-145, 2010.

SIGNORETTI, R. D. et al. Desenvolvimento corporal de novilhas leiteiras suplementadas com minerais inorgânicos e orgânicos em pastejo na época das águas. Revista Brasileira de Saude e Producao Animal, v. 14, n. 2, p. 336349, 2013.

SIMÕES, A. R. P. et al. Avaliação econômica de três diferentes sistemas de produção de leite na região do Alto Pantanal Sul-mato-grossense. Agrarian, v. 2, n. 5, p. 153-167, 2009.

SNIFFEN, C. J. et al. A net carbohydrate and protein system for evaluating cattle diets: II. Carbohydrate and protein availability. Journal of Animal Science, v. 40, n. 11, p. 3562-3577, 1992.

TEODORO, A. L. et al. Níveis de proteína na dieta de novilhas da raça pantaneira: Desempenho e digestibilidade aparente. Archivos de Zootecnia, v. 62, n. 239, p. 369-378, 2013.

TILLEY, J. M. A.; TERRY, R. A. A two-stage technique for the in vitro digestion of forage crops. Grass and forage science, v. 18, n. 2, p. 104-111, 1963.

VAN SOEST, P. J. Cell wall matrix interactions and degradation. Session synopsis. In: Forage cell wall structure and digestibility. Madison: American Society of Agronomy, 1993. p. 377-395. 